\title{
Changes in seasonal snow cover in Hindu Kush-Himalayan region
}

\author{
D. R. Gurung ${ }^{1}$, A. V. Kulkarni ${ }^{2}$, A. Giriraj ${ }^{1}$, K. S. Aung ${ }^{1}$, B. Shrestha ${ }^{1}$, and \\ J. Srinivasan ${ }^{2}$ \\ ${ }^{1}$ International Centre for Integrated Mountain Development (ICIMOD), P.O. Box 3226, \\ Kathmandu, Nepal \\ ${ }^{2}$ Divecha Center for Climate Change, Indian Institute of Science, Bangalore - 560 012, India \\ Received: 9 February 2011 - Accepted: 11 February 2011 - Published: 2 March 2011 \\ Correspondence to: D. R. Gurung (drgurung@icimod.org) \\ Published by Copernicus Publications on behalf of the European Geosciences Union.
}

\section{Abstract}

The changes in seasonal snow covered area in the Hindu Kush-Himalayan (HKH) region have been examined using Moderate - resolution Imaging Spectroradiometer (MODIS) 8-day standard snow products. The average snow covered area of the HKH 5 region based on satellite data from 2000 to 2010 is 0.76 million $\mathrm{km}^{2}$ which is $18.23 \%$ of the total geographical area of the region. The linear trend in annual snow cover from 2000 to 2010 is $-1.25 \pm 1.13 \%$. This is in consistent with earlier reported decline of the decade from 1990 to 2001 . A similar trend for western, central and eastern $\mathrm{HKH}$ region is $8.55 \pm 1.70 \%,+1.66 \% \pm 2.26 \%$ and $0.82 \pm 2.50 \%$, respectively. The snow

10 covered area in spring for $\mathrm{HKH}$ region indicates a declining trend $(-1.04 \pm 0.97 \%)$. The amount of annual snowfall is correlated with annual seasonal snow cover for the western Himalaya, indicating that changes in snow cover are primarily due to interannual variations in circulation patterns. Snow cover trends over a decade were also found to vary across seasonally and the region. Snow cover trends for western $\mathrm{HKH}$ are pos-

15 itive for all seasons. In central HKH the trend is positive $(+15.53 \pm 5.69 \%)$ in autumn and negative $(-03.68 \pm 3.01)$ in winter. In eastern $\mathrm{HKH}$ the trend is positive in summer $(+3.35 \pm 1.62 \%)$ and autumn $(+7.74 \pm 5.84 \%)$. The eastern and western region of $\mathrm{HKH}$ has an increasing trend of $10 \%$ to $12 \%$, while the central region has a declining trend of $12 \%$ to $14 \%$ in the decade between 2000 and 2010. Snow cover depletion curve plotted for the hydrological year 2000-2001 reveal peaks in the month of February with subsidiary peaks observed in November and December in all three regions of the $\mathrm{HKH}$.

\section{Introduction}

Hindu Kush-Himalaya $(\mathrm{HKH})$ is a major mountain range and geographically distributed in different countries which includes Afghanistan, Bhutan, China, India, Myanmar, Nepal and Pakistan. The region is a store house of vast reservoir of seasonal snow 
and glaciers, therefore, also known as third Polar Region. Many rivers originate from the region and their water supply is fed by snow and glacier melting and helps to support a large population along these rivers. However the extent of snow and glaciers are constantly changing with time, influencing runoff of streams originating from the

$5 \mathrm{HKH}$ region. The recent changes in glacial and snow extent are reported from different parts of HKH region, suggesting glacial retreat from $28 \%$ to $16 \%$ (Niederer et al., 2008; Kulkarni et al., 2010; Nie et al., 2010). These changes are mostly attributed to changing pattern of snowfall and temperature (Shekhar et al., 2010). In addition, some investigations suggest that warming trends are also due to additional absorption of so-

10 lar radiation by soot and also due to deposition of soot on snow and glaciers (Hansen and Nazarenko, 2004; Ramanathan et al., 2007; Satheesh et al., 2008; Chand et al., 2009). Recent investigations suggest that annual snow cover for $\mathrm{HKH}$ region has declined by $-16 \%$ per decade between 1990 and 2001 (Menon et al., 2010). In addition, model investigations suggest contribution of enhanced Indian black carbon (BC) to this 15 decline is approximately $36 \%$ (Menon et al., 2010). Therefore, it would be important to understand trend in seasonal snow cover changes in the $\mathrm{HKH}$ region for a decade from 2000 to 2010.

The HKH region characterized by large climate variability due to altitudinal differences results in large spatial variation in snow cover across the region (Immerzeel et 20 al., 2009; Pu et al., 2007). The variability of snow cover is also closely related to air temperature (Wang et al., 2008). Study from Northern Xinjiang indicates such variability is prominent during beginning of snow accumulation and ending of snow melt seasons (Wang et al., 2008). The Western Himalaya account for higher average snow cover due to higher mean elevation, influence of winter westerlies, and northerly latitude (Bookhagen and Burbank, 2010), resulting in west-east gradient of snow cover (Bookhagen and Burbank, 2010; Immerzeel et al., 2009). However, west-east gradient is subtle during summer suggesting similar snow cover area across the Himalaya (Bookhagen and Burbank, 2010). Timing of snow cover peak differs across under the influence of different weather systems. In Western Himalaya snow cover peaks in

February (Kirpalani et al., 2003), January in Kashmir valley (Negi et al., 2009), and end of March in Baspa basin (Kaur et al., 2009). In China snow peak is recorded in January for Qinghai-Xizang (Tibet) Plateau and mid-March for western China (Dahe et al., 2006). The initiation of snow depletion also depend on elevation: January for area 5 between 2000 and $4000 \mathrm{~m}$, March for area between 4000 and $6000 \mathrm{~m}$, and April in the region above $6000 \mathrm{~m}$ for Tibetan Plateau (Pu et al., 2007).

It is rather difficult to perform trend analysis due to availability of snow cover data of limited period. Trend for HKH region and vicinity based on 2000-2008 snow data yields significant negative trend only for winter snow cover both in the upper Indus basin and 10 entire region (Immerzeel et al., 2009). Similar trend of snow cover fraction, SCF, for Tibetan Plateau using snow data of $2000-2006$ is $-0.34 \%$ per year (Pu et al., 2007). In the north western region of China snow cover trend of 47 years (1951-1997) show slight increase (Dahe et al., 2006). Analysis of station data from 1957 to 1992 reveal striking increase in snow depth from Tibetan Plateau since 1980s (Dahe et al., 2006).

\section{Study site}

The geographical boundary of the HKH region includes the Karakorum, the Pamir, the Himalaya and other neighbouring ranges (www.icimod.org). The region includes eight countries namely Afghanistan, Bangladesh, Bhutan, China, India, Myanmar, Nepal and Pakistan (see Fig. 1). The east to west length of $\mathrm{HKH}$ region is approximately $3500 \mathrm{~km}$ 20 and covers approximately 4.2 million $\mathrm{km}^{2}$ in area. The altitude range is also vast and covers altitude from sea level to the Mount Everest, highest peak on the Earth. 


\section{Data sets}

\subsection{MODIS snow cover}

In this investigation data of Moderate resolution imaging and spectroradiometer (MODIS) sensor with spatial resolution of $500 \mathrm{~m}$ was used. The 8-day composite of 5 maximum snow cover from Terra (MOD10A2) and Aqua (MYD10A2) were used (Hall et al., 2002). The daily snow cover products generated by NASA Goddard Space Flight Center (GSFC) in Greenbelt, MD uses Normalized Difference Snow Index (NDSI) and composited into 8-day product which is made available by National Snow and Ice Data Center (NSIDC), Colorodo, USA. In this method reflectance in Bands 4 (0.545$10 \quad 0.565 \mu \mathrm{m})$ and $6(1.628-1.652 \mu \mathrm{m})$ was used along with numerous other threshold tests as described in Riggs et al. (2006), and a MODIS-derived cloud mask. The NDSI was calculated using following relationship (Hall et al., 1995):

$\mathrm{NDSI}=\frac{\text { Band } 4-\text { Band } 6}{\text { Band } 4+\text { Band } 6}$.

\subsection{Digital Elevation Model (DEM)}

15 The elevation data of Shuttle Radar Topography Mission (SRTM) was used for deriving topographic variables: aspect, slope and elevation. The SRTM DEM at $90 \mathrm{~m}$ spatial resolution was re-sampled to $500 \mathrm{~m}$ to make it consistent with snow data.

\section{Methods}

MODIS 8-day product for HKH region contained significant percentage of cloud pixels. To remove cloud pixels, series of procedure was used. These include combining Terra and Aqua images, combining adjacent day products, spatial continuity and altitude threshold. Some of these procedures in detail are explained in Gafurov and Bárdossy (2009).

\subsection{Combining Terra and Aqua}

The Terra and Aqua is collected in the morning and afternoon, respectively. It can change locations of cloud pixels and land features below the clouds can be identified, if data of both the sensors are combined. The procedure for combination is explained 5 in following relationship.

$S(x, y, t)=\max \left(S_{(x, y, t)}^{\mathrm{A}}, S_{(x, y, t)}^{\top}\right)$

where $y$ is the index for row (vertical); $x$ is the index for column (horizontal); $t$ is the index for day (temporal) of pixel $S . S^{A}$ and $S^{\top}$ stand for the Aqua and Terra pixels, respectively. This step has successfully removed $\sim 40 \%$ of cloud pixels in $\mathrm{HKH}$ region 10 from the 8-day standard MODIS products.

\subsection{Temporal filter}

After combining Terra and Aqua data of 8 days, if any pixel is identified as cloud then temporal filter was applied to identify land feature below cloud. A similar method has been used by Hall et al. (2010). Initially same class as given in backward 8-day product was used and then subsequently, if pixel is still cloud then forward 8-day product was used. Those pixels as cloud in all three set of 8-day products will be retained as cloud. The relationship is explained in Eq. (3).

$S(x, y, t)=1$ if $S(x, y, t-8)=1$ or $S(x, y, t+8)=1$

where $S-8, S$ and $S+8$ are three consecutive set of 8-day products and 1 corresponds

20 to snow cover and 0 for land cover. Temporal filter has removed additional $\sim 50 \%$ of cloud in $\mathrm{HKH}$ region.

\subsection{Spatial filter}

To remove residual cloud pixels, spatial filter was used. Different filter sizes were analysed and results plotted for different scenes. In terms of performance $7 \times 7$ kernel size 
indicated maximum potential to remove cloud pixels (Fig. 2). This filter could remove additional $5 \%$ cloud cover.

\subsection{Altitude based masking}

Global MODIS snow product, can classify pixels erroneously as snow in lower altitudes 5 regions of India, Bhutan and Nepal. Therefore, threshold value based on altitude was used to remove erroneous snow pixels. The different threshold values were applied for different regions of the HKH based on literature survey and personal communication (Jain et al., 2009; Kulkarni et al., 2010).

\subsection{Integrated tool for MODIS Snow processing and analysis}

10 An integrated tool for MODIS Snow processing and analysis was developed to automate the pre-processing of huge volume of snow data. Tool is capable of contextualizing global MODIS snow data to HKH region, implement cloud filtering steps, and derive snow statistics based on altitude, aspect and slope.

The core program was written in $C$ using free and open source image handling li15 braries which is distributed under General Public License. A Graphic User Interface is written in Microsoft Visual C\# 2008 using Microsoft Visual Studio 2008.

\section{Results and discussion}

\subsection{Product accuracy}

Inter-comparison of enhanced MODIS snow cover product with snow cover product 20 from Advance Wide Field Sensor (AWiFS) images from Indian Remote Sensing Satellite (IRS) of 16 and 21 January 2006, resampled to $500 \mathrm{~m}$ resulted in overall accuracy of $93 \%$ and Kappa coefficient was 0 . The overall accuracy and kappa statistics were estimated based on the error matrix using 100 random points (Congalton et al.,

1999).To validate snow cover data, the variation in snowfall data at Gulmarg, HaddanTaj and Dhundi locations in Western Himalaya was correlated with percentage of MODIS snow cover at the same locations. The graphs of HaddanTaj, Gulmargand, Dhundi are shown in Fig(s). 3, 4 and 5, respectively. These graphs suggest good cor5 relation between amount of snowfall and percentage of snow cover, indicating utility of snow products for trend analysis in $\mathrm{HKH}$ region.

\subsection{Decadal snow cover analysis}

The decadal change of snow cover for HKH region, from 2000 to 2010, was estimated using annual mean snow cover area (SCA) derived from standard 8-day MODIS snow product of Terra satellite. The trend is declining $(-1.25 \pm 1.13 \%)$ which is different than earlier reported for 2000-2008 (Immerzeel et al., 2009), and amount of decline is significantly less than reported for an earlier decade between 1990 and 2010 (Menon et al., 2010). Similarly snow cover trend was estimated for western, central and eastern regions of HKH (Fig. 1). These regions were delineated based on references

15 (Fig. 1, Kirpalani et al., 2003; Zurick et al., 2005). Accordingly west of Nepal is considered western HKH region, stretch between Nepal and Bhutan is central HKH region, and region east of Bhutan (including Bhutan) is eastern HKH region. In the western $\mathrm{HKH}$ region, decadal snow cover from year 2000 has increased by $+8.55 \pm 1.70 \%$ (Table 1). Similar trend for central and eastern HKH region was not statistically significant.

20 To validate these observations, the field snowfall data of western Himalaya was used (Shekhar et al., 2010). The snowfall data was available for 18 stations distributed from Karakoram to PirPanjal mountain range (Shekhar et al., 2010). The annual linear trend in snowfall data for a decade from year 2000 based on snowfall data from 2000 to 2008 has shown increasing trend (Shekhar et al., 2010). Intra-annual variation of snow

25 cover for entire HKH region was studied using monthly mean SCA. Similar to Yangtse and Yellow River basins (Immerzeel et al., 2010) two snow cover peaks was observed, one in the month of February with subsidiary peaks were observed in November and December. 
To understand the seasonal variation of SCA in HKH region, mean monthly SCA data was analysed for winter (December-March), spring (April-June), summer (July-September) and autumn (October and November) seasons between 2000 and 2010. In present investigation significant declining trend was observed only in spring

$5 \quad(-1.04 \pm 0.97 \%)$ and no significant declining trend was observed in winter (Table 1). Analysis in different seasons suggest that the western $\mathrm{HKH}$ region has gained SCA in all seasons and eastern $\mathrm{HKH}$ has gained in summer $(+3.35 \pm 1.62 \%)$ and autumn $(+7.74 \pm 5.84 \%)$. For central $\mathrm{HKH}$, the SCA in winter show declining trend ($3.68 \pm 3.01 \%)$ while it is increasing $(+15.53 \pm 5.69 \%)$ in autumn. Using mean monthly

10 SCA for elevation bands (<1000 m, 1000-2000 m, 3000-5000 m, 5000-7000 m and $>7000 \mathrm{~m}$ ), snow cover depletion curve was plotted for hydrological years (July 2000June 2001). Consistent with the observation in Tibetan Plateau (Pu et al., 2007), beginning of snow depletion is found to be delayed with elevation across $\mathrm{HKH}$ region. Through the analysis of mean monthly SCA for different season for this decade, larger

15 fluctuations in seasonal snow cover were observed in autumn, indicating simultaneous snow accumulation and ablation process.

To understand possible changes in snow cover pattern, the mean annual snowfall data was correlated with mean vertical velocity at $500 \mathrm{mb}$ in winter period for the Western Himalaya. The National Center for Environment Prediction/National Center for At-

20 mospheric Research (NCEP/NCAR) reanalysis data was used to estimate mean winter vertical velocity at $500 \mathrm{mb}$ in Western Himalaya. The good correlation (see Fig. 8) suggests that changes in snow cover are due to inter annual variations in circulation pattern.

For estimation of SCA for the HKH region, enhanced MODIS snow cover prod25 uct generated using steps described in Sect. 4 and available since 2002 was used. Mean annual SCA for last 9 years (2002-2010) show variation ranging from 0.70 million $\mathrm{km}^{2}$ in 2002 to 0.84 million $\mathrm{km}^{2}$ in 2005 . Maximum and minimum 8 -day SCA is 1.79 million $\mathrm{km}^{2}$ constituting $42.89 \%$ and 0.18 million $\mathrm{km}^{2}$ constituting $4.32 \%$ of the total land area, respectively. Monthly mean snow cover depicting the annual cycle

763

shows February has received maximum snow while July has recorded least snow extend in last decade. It is also February and July that has maximum and minimum mean monthly SCA variation respectively over the period of 2002-2010.

\section{Conclusions}

5 In this investigation different techniques were used to remove cloud cover and this has improved usability of snow cover product. The snow cover products were further validated using snowfall data of the Western Himalaya and high resolution AWiFS data of the Eastern Himalaya.

The average snow cover area of the Hindu Kush-Himalayan region based on satellite

10 data from 2000 to 2010 is 0.76 million $\mathrm{km}^{2}$ which is $18.23 \%$ of the total geographical area. The linear trend in annual snow cover from 2000 to 2010 is $-1.25 \pm 1.13 \%$. This is significantly different from earlier reported for 2000-2008 (Immerzeel et al., 2009), and decline is significantly less than reported for an earlier decade between 1990 and 2010 (Menon et al., 2010). The good correlation between snow cover, mean annual

15 snowfall and mean annual vertical velocity at $500 \mathrm{mb}$ in the winter period for the Western Himalaya suggest the changes in snow cover between 2000 and 2010 are due to inter annual variations in circulation pattern. Snow cover trend over 2000-2010 was also found to vary across seasons and geographical extent. The snow cover area in spring indicates declining trend $(-1.04 \pm 0.97 \%)$ for Hind Kush-Himalayan region. The

20 western and eastern region of Hind Kush-Himalayan has increasing trend $(10 \%-12 \%)$, while central region has declining trend $(12 \%-14 \%)$ in this decade. Intra-annual variation showed areal extent of snow cover peaks in the month of February with subsidiary peaks were observed in November and December.

Acknowledgements. This paper is based on the work supported by the Swedish International 25 Development Cooperation Agency (Sida) under the project "Too much water, too little water Adaptation strategies to climate induced water stress and hazards in the Greater Himalayan region". The authors are grateful to Andreas Kaab, University of Zurich, Switzerland, and Dorothy 
K. Hall, National Aeronautics and Space Administration (NASA), who during the review phase provided crucial input which helped improve the manuscript. Thanks are due to ICIMOD colleagues, professionals of collaborating institutions, and independent experts who contributed significantly during various parts of the project. Gauri Dangol and Pardeep Dangol of ICIMOD

5 deserve special mention for their help in analysing snow cover data and graphics. Finally, authors would like to remember and thank late Monica Moktan who as a Sr. Program Assistant was instrumental in functioning of the project in the initial phase.

\section{References}

Bookhagen, B. and Burbank, D. W.: Toward a complete Himalayan hydrological budget: Spatiotemporal distribution of snowmelt and rainfall and their impact on river discharge, J. Geophys. Res., 115, F03019, doi:10.1029/2009JF001426, 2010.

Chand, D., Wood, R., Satheesh, S. K., Charlson, R. J., and Anderson, T. L.: Satellite-derived direct radiative effect of aerosols dependent on cloud cover, Nat. Geosci., 2, 181-184, doi:10.1038/ngeo437, 2009.

15 Congalton, R. G., Green, K., and Press, C. R. C.: Assesssing the accuracy of remotely sensed data principles and practices, Mapping science series, Lewis Publications, Boca Raton, 1999.

Dahe, Q., Shiyin, L., and Peiji, L.: Snow cover distribution, variability, and response to climate change in western China, J. Climate, 19, 1820-1833, 2006.

20 Gafurov, A. and Bárdossy, A.: Cloud removal methodology from MODIS snow cover product, Hydrol. Earth Syst. Sci., 13, 1361-1373, doi:10.5194/hess-13-1361-2009, 2009.

Hall, D. K., Riggs, G. A., and Salomonson, V. V.: Development of methods for mapping global snow cover using moderate resolution imaging spectroradiometer data, Remote Sens. Environ., 54(2), 127-140, doi:10.1016/0034-4257(95)00137-P, 1995.

25 Hall, D. K., Riggs, G. A., Salomonson, V. V., DiGirolamo, N. E., and Bayr, K. J.: MODIS snowcover products, Remote Sens. Environ., 83, 181-194, 2002.

Hall, D. K., Riggs, G. A., Foster, J. L., and Kumar, S. V.: Development and evaluation of a cloud-gap-filled MODIS daily snow-cover product, Remote Sens. Environ., 114, 496-503, 2010.

Hansen, J. and Nazarenko, L.: Soot climate forcing via snow and ice albedos, P. Natl. Acad. Sci. USA, 101, 423-428, doi:10.1073/pnas.2237157100, 2004.

Immerzeel, W. W., Droogers, P., de Jong, S. M., and Bierkens, M. F. P.: Large-scale monitoring of snow cover and runoff simulation in Himalayan river basins using remote sensing, Remote Sens. Environ., 113, 40-49, doi:10.1016/j.rse.2008.08.010, 2009.

Jain, S., Goswami, A., and Saraf, A.: Role of Elevation and Aspect in Snow Distribution in Western Himalaya, Water Resour. Manag., 23, 71-83, doi:10.1007/s11269-008-9265-5, 2009.

Kaur, R., Saikumar, D., Kulkarni, A.V., and Chaudhary, B.S.: Variations in snow cover and snowline altitude in Baspa Basin, Current Science, 96, 1255-1258, 2009.

10 Kripalani, R. H., Kulkarni, A., and Sabade, S. S.: Western Himalayan snow cover and Indian monsoon rainfall: A re-examination with INSAT and NCEP/NCAR data, Theor. Appl. Climatol., 74, 1-18, doi:10.1007/s00704-002-0699-z, 2003.

Kulkarni, A. V., Singh, S. K., Mathur, P., and Mishra, V. D.: Algorithm to monitor snow cover using AWiFS data of RESOURCESAT-1 for the Himalayan region, Int. J. Remote Sens., 27, 2449-2457, doi:10.1080/01431160500497820, 2006.

Kulkarni, A. V., Rathore, B. P., Singh, S. K., and Ajai: Distribution of seasonal snow cover in central and western Himalaya, Ann. Glaciol., 51(54), 123-128, doi:10.3189/172756410791386445, 2010.

Menon, S., Koch, D., Beig, G., Sahu, S., Fasullo, J., and Orlikowski, D.: Black carbon aerosols and the third polar ice cap, Atmos. Chem. Phys., 10, 4559-4571, doi:10.5194/acp-10-45592010, 2010.

Negi, H. S., Kulkarni, A. V., and Semwal, B. S.: Estimation of snow cover distribution in Beas basin, Indian Himalaya using satellite data and ground measurements, J. Earth Syst. Sci., 118(5), 525-538, doi:10.1007/s12040-009-0039-0, 2009.

25 Nie, Y., Zhang, Y., Liu, L., and Zhang, J.: Glacial change in the vicinity of Mt. Qomolangma (Everest), central high Himalayas since 1976, J. Geogr. Sci., 20(5), 667-686, doi:10.1007/s11442-010-0803-8, 2010.

Niederer, P., Bilenko, V., Ershova, N., Hurni, H., Yerokhin, S., and Maselli, D.: Tracing glacier wastage in the Northern Tien Shan (Kyrgyzstan/Central Asia) over the last 40 years, Climatic Change, 86(1-2), 227-234, doi:10.1007/s10584-007-9288-6, 2008.

$\mathrm{Pu}, \mathrm{Z}$., Xu, L., and Salomonson, V.: MODIS/Terra observed seasonal variations of snow cover over the Tibetan Plateau, Geophys. Res. Lett., 34, L06706, doi:10.1029/2007GL029262, 2007. 
Ramanathan, V., Ramana, M. V., Roberts, G., Kim, D., Corrigan, C., Chung, C., and Winker, D.: Warming trends in Asia amplified by brown cloud solar absorption, Nature, 448, 575-578, doi:10.1038/nature06019, 2007.

Satheesh, S. K., Krishna Moorthy, K., Suresh Babu, S., Vinoj, V., and Dutt, C. B. S.: Climate im-

5 plications of large warming by elevated aerosol over India, Geophys. Res. Lett., 35, L19809, doi:10.1029/2008GL034944, 2008.

Shekhar, M. S., Chand, H., Kumar, S., Srinivasan, K., and Ganju, A.: Climate-change studies in the western Himalaya, Ann. Glaciol., 51(54), 105-112, doi:10.3189/172756410791386508, 2010.

10 Wang, X., Xie, H., and Liang, T.: Evaluation of MODIS snow cover and cloud mask and its application in Northern Xinjiang, China, Remote Sens. Environ., 112, 1497-1513, doi:10.1016/j.rse.2007.05.016, 2008.

Zurick, D., Pacheco, J., Shrestha, B., and Bajracharya, B.: Atlas of the Himalaya, ICIMOD Publication, 2005.

Table 1. Linear trend (2000-2010) of snow cover for entire HKH region and different region of $\mathrm{HKH}$. Bold numbers indicates significant trend.

\begin{tabular}{lcccc}
\hline & HKH region & Western HKH & Central HKH & Eastern HKH \\
\hline Spring & $-1.04 \% \pm 0.97$ & $+4.04 \pm 2.02 \%$ & $0.56 \pm 2.67 \%$ & $-0.89 \pm 1.23 \%$ \\
Summer & $-0.01 \% \pm 0.46$ & $+2.58 \pm 0.74 \%$ & $+0.47 \pm 0.65 \%$ & $+3.35 \pm 1.62 \%$ \\
Autumn & $+5.63 \% \pm 8.39$ & $+3.69 \pm 2.64 \%$ & $+15.53 \pm 5.69 \%$ & $+7.74 \pm 5.84 \%$ \\
Winter & $-0.54 \% \pm 0.67$ & $+5.08 \pm 2.48 \%$ & $-3.68 \pm 3.01 \%$ & $+1.61 \pm 3.12 \%$ \\
Annual & $-1.25 \pm 1.13 \%$ & $+8.55 \pm 1.70 \%$ & $+1.66 \% \pm 2.26$ & $+0.82 \pm 2.50 \%$ \\
\hline
\end{tabular}




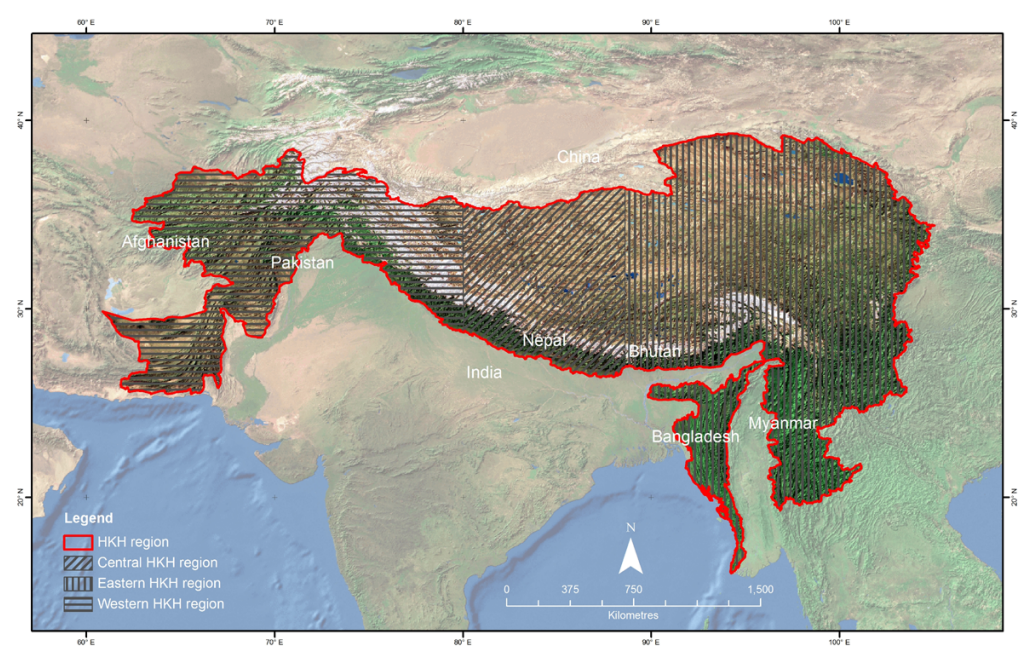

Fig. 1. The map showing extent of Hindu Kush-Himalayan $(\mathrm{HKH})$ region.

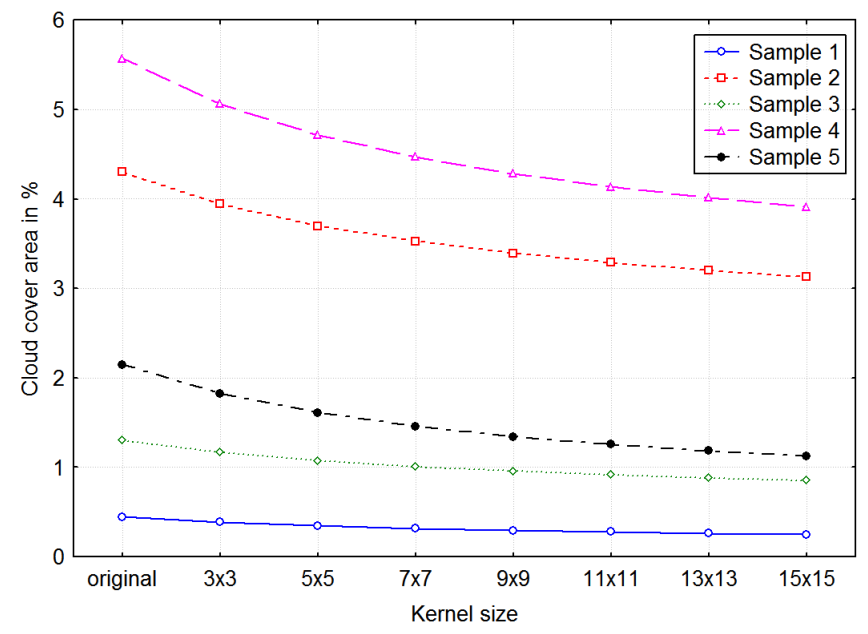

Fig. 2. Percentage of cloud cover present in MODIS snow cover product after implementing spatial filter with different kernel size. Samples 1 to 5 represent situation of improvement in 5 different snow cover product of different dates. 


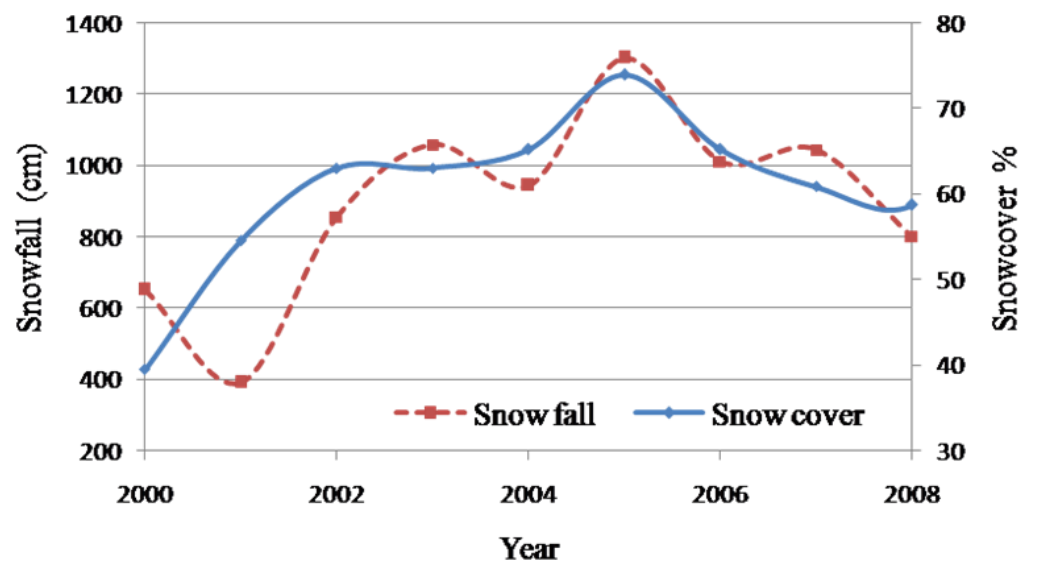

Fig. 3. Plot showing amount of snowfall and percentage of snow cover at HaddanTaj in Jammu and Kashmir, India.

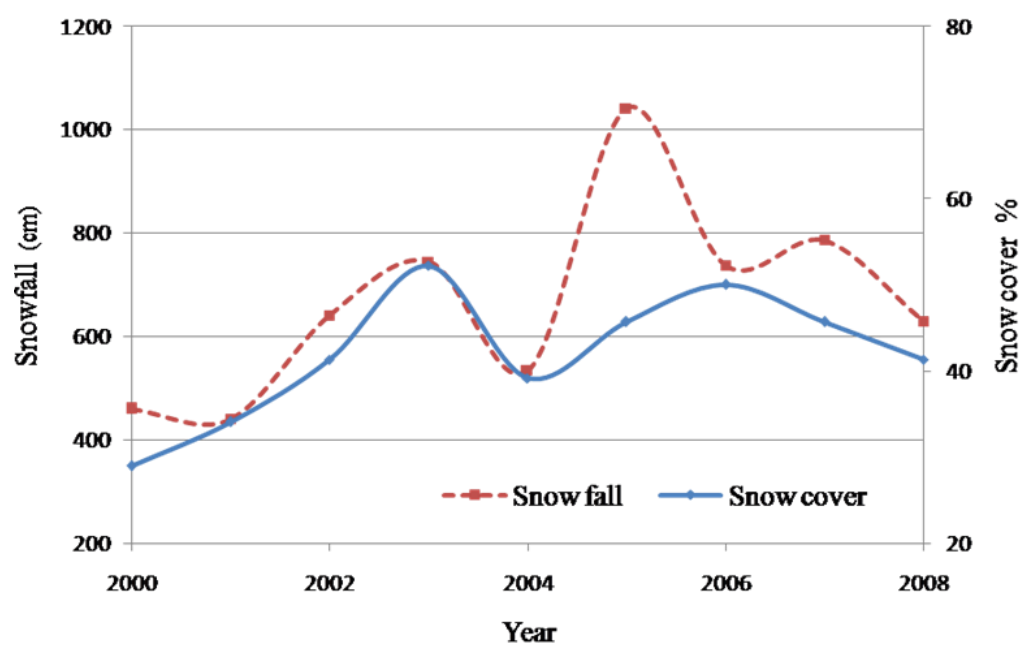

Fig. 4. Plot showing amount of snowfall and percentage of snow cover at Gulmarg in Jammu and Kashmir, India. 


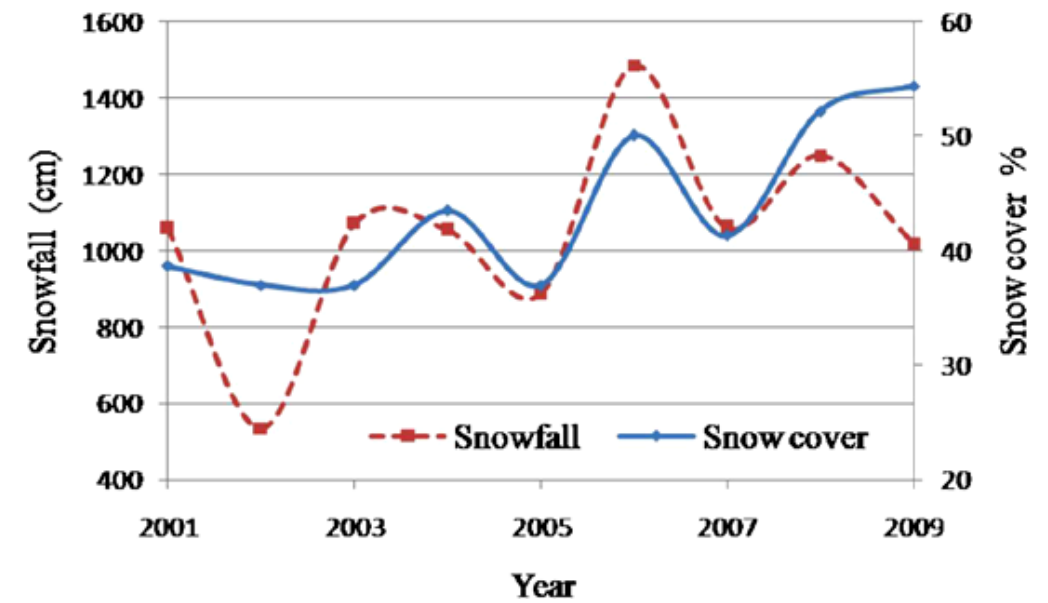

Fig. 5. Plot showing amount of snowfall and percentage of snow cover at Dhundi in Himachal Pradesh, India.

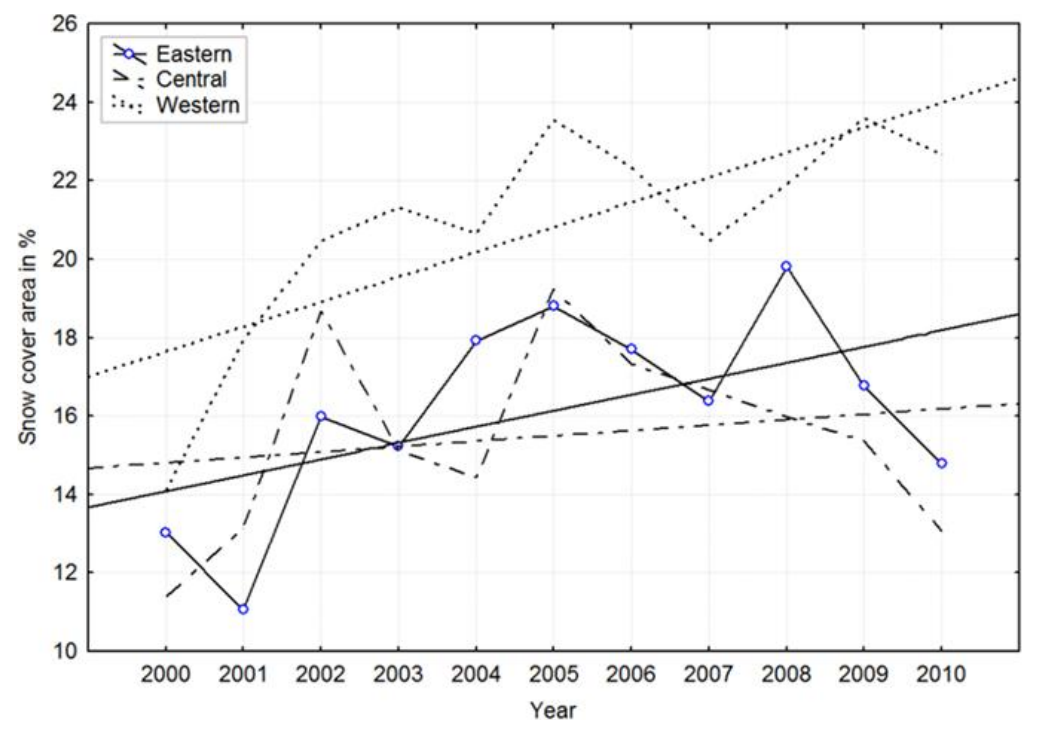

Fig. 6. Inter-annual decadal variation of percent snow cover area for eastern, central and western regions of the Hindu Kush-Himalaya. 


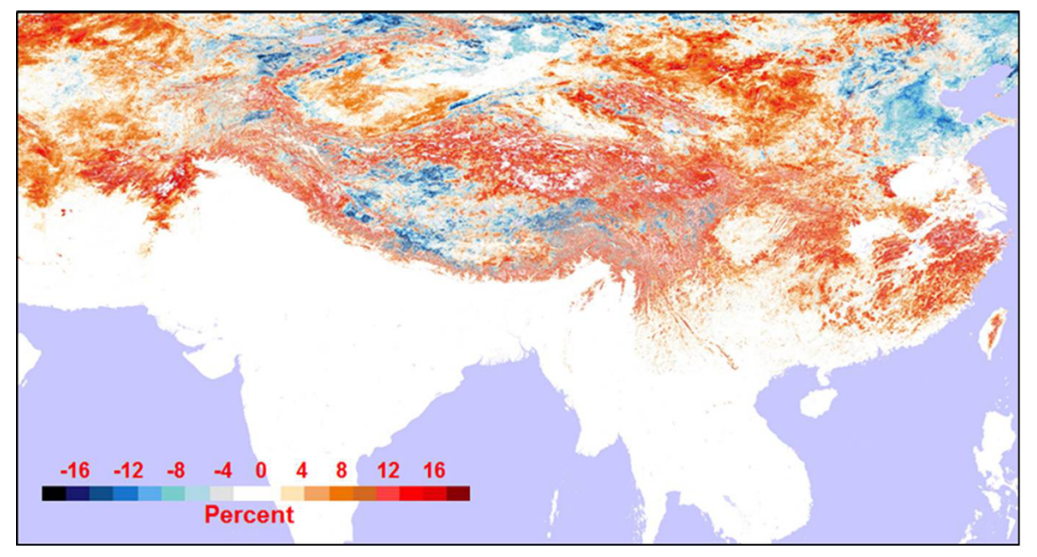

Fig. 7. Decadal snow map showing percent change in snow cover area based on linear regression model for the Hindu Kush-Himalayan region.

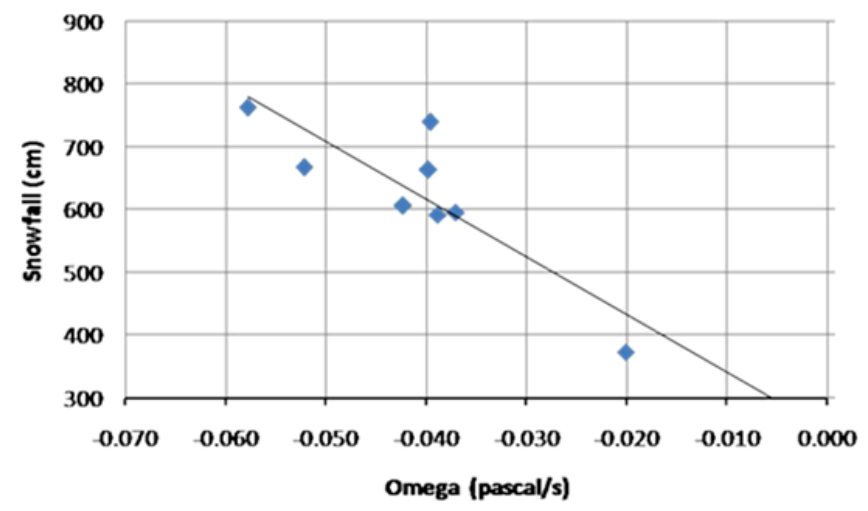

Fig. 8. Relationship between snowfall and omega for the western Himalaya region. 


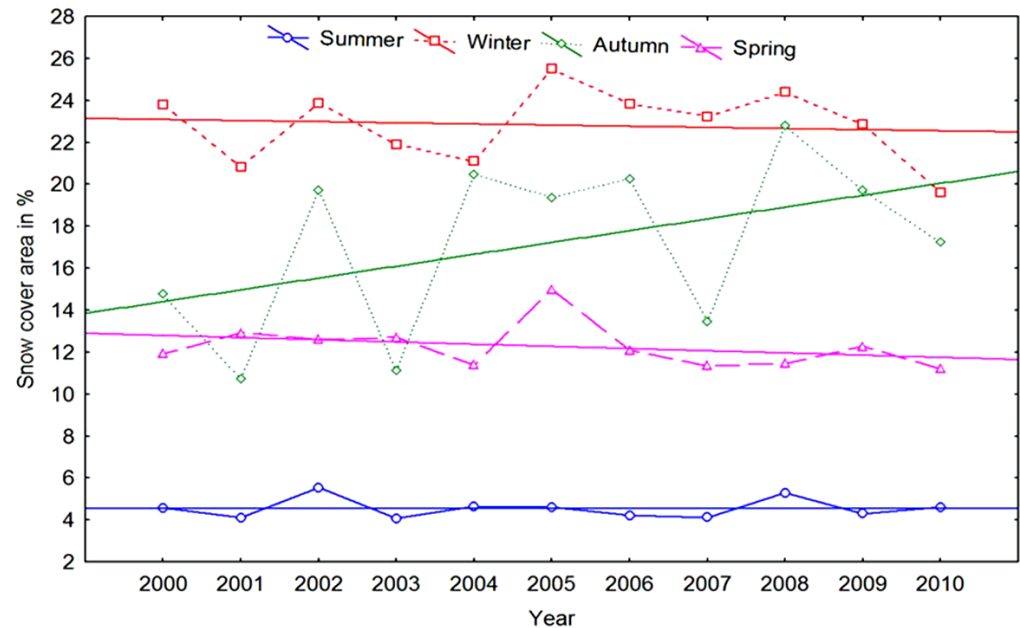

Fig. 9. Decadal seasonal snow cover trend (2000-2010) for the Hindu Kush-Himalayan region. 